\title{
Cervical Mucinous Adenocarcinoma, Intestinal-Type
}

National Cancer Institute

\section{Source}

National Cancer Institute. Cervical Mucinous Adenocarcinoma, Intestinal-Type. NCI

Thesaurus. Code C40203.

A cervical mucinous adenocarcinoma that resembles the large intestinal adenocarcinoma. 